\title{
FORMAÇÃO DE PROFESSORES PARA O RECONHECIMENTO DAS ALTAS HABILIDADES/SUPERDOTAÇÃO
}

\author{
Denise Rocha Belort Arantes-Brero*
}

Vera Lúcia Messias Fialho Capellini**

\begin{abstract}
RESUMO: A legislação ampara o atendimento aos estudantes com altas habilidades/superdotação (AH/SD); ainda se observa, entretanto, a invisibilidade desses estudantes. Formação continuada é uma estratégia viável para superar esse problema, pois os professores poderão identificá-los com mais precisão. Este trabalho objetiva avaliar a efetividade de um programa de formação continuada para professores do ensino comum, comparando os resultados obtidos com o preenchimento do questionário Avaliação de conhecimentos acerca da superdotação (ACAS) antes (pré-teste) e após (pós-teste) a oferta de um curso semipresencial sobre AH/SD. A pesquisa, de caráter descritivo, contou com a participação de 30 professores, sendo $97 \%$ do sexo feminino, os quais responderam ao ACAS, que foi preenchido novamente no final do curso, junto com um formulário de avaliação. Os dados foram analisados pelo softwvare Statistical Package for the Social Sciences e pelo Iramuteq. Em relação à avaliação do curso, $100 \%$ dos cursistas apontaram que os objetivos foram cumpridos. Os resultados indicam melhora no desempenho após a intervenção. Conclui-se que os professores compreenderam o tema, sendo capazes de reconhecer e atender estudantes com características de AH/SD.
\end{abstract}

Palavras-chave: Formação de professores. Talento. Educação especial. Altas habilidades. Superdotação.

\section{TEACHER TRAINING FOR RECOGNITION OF HIGH ABILITIES/GIFTEDNESS}

\begin{abstract}
The legislation supports the attendance of students with high abilities/giftedness, however, its invisibility is still observed. Continuing education is a viable strategy to overcome this problem, as teachers will be able to identify them more accurately. This work aims to evaluate the effectiveness of a continuing education program for teachers of common education by comparing the results obtained by completing the questionnaire "Assessment of knowledge about giftedness (ACAS)" before (pre-test) and after (post-test) offering a semipresential course on high abilities/giftedness. This research of a descriptive character, counted on the participation of 30 teachers, $97 \%$ of whom were female, who answered the questionnaire Assessment of knowledge about giftedness, which was completed again at the end of the course along with the evaluation form. The data were analyzed by the software Statistical Package for the Social Sciences and by Iramuteq. Regarding the evaluation of the course, $100 \%$ of the participants pointed out that the objectives were fulfilled. The results indicate an improvement in performance after the intervention. It is possible to conclude that the teachers understood the theme being able to recognize and attend students with characteristics of high abilities/giftedness.
\end{abstract}

KEYWORDS: Teacher training. Talent. Special education. Giftedness. High abilities.

\footnotetext{
* Doutora em Psicologia do Desenvolvimento e Aprendizagem pela UNESP - Bauru. Atual Presidente do Conselho Brasileiro para Superdotação - ConBraSD, E-mail: drbarantes@gmail.com; ORCID: https://orcid.org/0000-0001-9282-6755.

** Pós-Doutorado na Universidade de Alcalá- Espanha, Profa. Adjunta do Departamento de Educação, do Programa de Pósgraduação em Psicologia do Desenvolvimento e Aprendizagem e do Programa de Mestrado Profissional em Docência para a Educação Básica, da FC/ UNESP- Bauru. Vice-Diretora da Faculdade de Ciências - FC/UNESP-Bauru; E-mail: vera.capellini@unesp.br. ORCID: https://orcid.org/0000-0002-9184-8319.
} 


\section{Introdução}

Ao analisar os documentos legais relativos ao público-alvo da educação especial, nota-se que vários deles amparam as altas habilidades/superdotação (AH/SD), garantindo acesso, permanência e atendimento na escola comum, por meio da aceleração de estudos ou do enriquecimento curricular. Dentre eles, destaca-se a Lei 9.394 (BRASIL, 1996), que institui as diretrizes e bases da educação, alterada pela Lei $n^{\circ} 13.234$ (BRASIL, 2015), a qual, por sua vez, prevê o estabelecimento de diretrizes e procedimentos para identificação, cadastramento e atendimento de estudantes com AH/SD em todos os níveis de ensino; a Política Nacional de Educação Especial na Perspectiva da Educação Inclusiva (BRASIL, 2008), a Resolução CNE/CEB 4 (BRASIL, 2009) e o Decreto 7.611 (BRASIL, 2011).

Apesar dessas garantias, observa-se que, na prática, em sua grande maioria, esses estudantes permanecem sem reconhecimento e sem o atendimento às suas necessidades específicas durante todo o período de escolarização (PÉREZ; FREITAS, 2011). Prova disso é que, em 2020, apenas 24.424 estudantes do território brasileiro estavam cadastrados como tendo AH/SD no Censo Escolar, o que representa 0,051\% dos 47.295.294 de estudantes matriculados na educação básica (INEP, 2020).

Essa proporção está longe do ideal apontado pelo Relatório de Marland (1972), o qual estima que, no mínimo, 3\% a 5\% da população apresentam AH/SD. Deste modo, teríamos, apenas na Educação Básica, pelo menos-1,41 milhões de estudantes superdotados, que permanecem invisíveis nas escolas, apesar de não se tratar de um fenômeno tão raro (SILVA-SCHRÖEDER, 2020) e nem restrito às camadas mais privilegiadas da população (ANTIPOFF; CAMPOS, 2010).

O reconhecimento e o atendimento especializado fazem-se necessários para promover a autorrealização e aumentar o número de pessoas que possam auxiliar na solução de problemas da civilização contemporânea, por meio da produção de conhecimentos (RENZULLI, 2014).

Nesse sentido, é necessário enfatizar o papel fundamental do professor no reconhecimento e encorajamento desses potenciais. A literatura, no entanto, aponta dificuldades encontradas pelos mestres para identificar estudantes com indícios de AH/SD em suas turmas, denunciando uma falha do ensino superior na disseminação desse conhecimento (BAHIENSE; ROSSETI, 2014; BRUM, 2014; ALENCAR; MARTINS, 2011; MARTINS; CHACON; ALMEIDA, 2018; RAMALHO et al., 2016).

Os mitos acerca da superdotação prejudicam sobremaneira o reconhecimento e atendimento a esses estudantes (MANSO, 2012; PÉREZ, 2003). Além disso, é preciso considerar que, apesar de existirem características que auxiliam no reconhecimento destes potenciais, é impossível apreender toda a multiplicidade de possibilidades existentes no ser humano (ARANTES-BRERO, 2016, 2020).

A deficiência na formação docente constitui-se em um enorme obstáculo para a efetivação de práticas inclusivas que valorizem a singularidade de cada estudante (CAPELLINI, 2018; LÔBO, 2016; MORI; BRANDÃO, 2009). Assim, a formação em serviço ou continuada, precisa ser estimulada (BERGAMIN, 2018; LOPES; LENHARO; CAPELLINI, 2014), implementada como uma política 
pública (MARTINS; ALENCAR, 2011), mostrando-se uma estratégia viável para a formação docente e deve ser realizada a partir de vivências concretas dos professores, valorizando a reflexão sobre a prática (MARTINS; CHACON, 2012).

Estudos de revisão de literatura (BORGES, 2016; MATOS et al., 2016) reforçam a importância da formação continuada, tendo em vista que ela instrumentaliza o professor para exercer seu papel a partir da reflexão entre teoria e prática, aproximando a universidade da escola. É necessária, entretanto, a realização de novos estudos que auxiliem na construção de instrumentos para a identificação de estudantes com características de AH/SD (MARTINS; PEDRO; OGEDA, 2016; SABBAG; ARANTES-BRERO, 2017).

Essa formação deve oportunizar condições para que o professor perceba indicadores de AH/SD por meio da oferta de conceitos teóricos e práticos, bem como o conhecimento dos instrumentos disponíveis para as escolas (SOARES; CHACON, 2016), tais como os propostos pelo modelo de enriquecimento escolar delineado por Renzulli (2018).

Desse modo, este estudo objetiva avaliar a efetividade de um programa de formação continuada para professores do ensino comum, comparando os resultados obtidos com o preenchimento do questionário "Avaliação de conhecimentos acerca da superdotação (ACAS)” antes (pré-teste) e após (pósteste) a oferta de um curso semipresencial sobre AH/SD.

\section{Método}

Esta pesquisa tem caráter descritivo (COZBY, 2003) e, obedecendo aos aspectos éticos contidos na Resolução CONEP n466/2012, foi aprovada pelo Comitê de Ética sob o número 2.011.876.

A formação continuada deu-se por meio do curso de extensão "Atendimento escolar ao estudante com altas habilidades/superdotação", oferecido pelo Ambiente Virtual de Aprendizagem (AVA) da Universidade Estadual Paulista (UNESP) com duração de 11 semanas. Os encontros presenciais foram realizados no anfiteatro do Departamento de Educação da UNESP, campus Bauru, em cinco sábados, das $8 \mathrm{~h}$ às $12 \mathrm{~h}$, durante os meses de maio, junho e julho de 2018.

Participaram 30 professores das redes municipal e estadual. Vale ressaltar que o curso iniciou com 48 inscritos e terminou com 40 concluintes, sendo 38 aprovados, havendo 10 desistências. No entanto, alguns cursistas faltaram ao último encontro e não responderam aos questionários finais sendo excluídos da amostra analisada. Foram recebidos 40 questionários ACAS no início do curso e 30 ao final. Desse modo, como a pesquisa objetivava avaliar os efeitos de um programa de formação de professores por meio deste instrumento, foram descartados aqueles preenchidos somente no primeiro encontro, tendo sido analisados os 30 respondidos pelos participantes antes e após a intervenção.

Para coleta dos dados foram utilizados o Questionário "Avaliação de conhecimentos acerca da superdotação (ACAS)" elaborado por Rodrigues (2012) a partir de Winner (1998) e o Formulário de 
Avaliação do Curso (FAC), elaborado pela pesquisadora. O questionário continha perguntas sobre satisfação em relação ao curso, grau de dificuldade quanto ao uso da plataforma, avaliação da organização do curso, do acompanhamento dos tutores e da qualidade dos professores. O participante respondeu a cada pergunta assinalando uma das opções: ótimo, bom, regular e ruim e esse preenchimento deu-se de forma anônima. Ao final, os cursistas deveriam escrever se recomendariam o curso, se ele contribuiu para sua prática e poderiam deixar comentários e sugestões.

\section{Procedimentos de intervenção}

O curso foi elaborado e inserido no Ambiente Virtual de Aprendizagem (AVA) e, em seguida, cadastrado na Pró-Reitoria de Extensão Universitária (PROEX) como curso de extensão, sendo solicitada autorização para sua realização junto à Secretaria de Estado da Educação de São Paulo.

Sua divulgação foi realizada por meio de ofício enviado à Dirigente Regional de Ensino e à Secretária Municipal de Educação e os professores interessados fizeram a inscrição on-line.

Sua oferta deu-se na modalidade semipresencial, com 66 horas de duração, sendo 46 horas on-line e 20 horas distribuídas em cinco encontros presenciais de 4 horas. O número de vagas oferecidas foi 60. O curso foi organizado em onze semanas on-line, intercaladas com cinco encontros presenciais. Seu objetivo era orientar os professores sobre procedimentos para identificação e atendimento aos estudantes com AH/SD no contexto escolar. O conteúdo programático foi dividido nas seguintes disciplinas:

1. D1 - Diversidade e Cultura Inclusiva

2. D2 - Políticas Públicas para estudantes com AH/SD

3. D3 - Contextualização e conceito das AH/SD

4. D4 - Avaliação de competências e necessidades de estudantes com AH/SD

5. D5 - Escolarização de estudantes com AH/SD

6. D6 - Trabalho colaborativo entre o professor da sala comum e o especializado

7. D7 - Tecnologias Educacionais

As disciplinas foram organizadas no AVA de modo que cada uma continha um texto introdutório sobre os objetivos da semana, textos e artigos para leitura, vídeos e uma tarefa a ser realizada e postada na plataforma até o final da semana.

Algumas semanas previram a realização de fóruns com vistas a fomentar a discussão de ideias entre os participantes e o aprendizado colaborativo. Além do material oferecido, havia o 
acompanhamento de um tutor ${ }^{1}$ com conhecimentos sobre a temática das AH/SD, que mediava a realização das atividades tanto no AVA quanto nos encontros presenciais. Também foram oferecidos dois canais de comunicação entre os cursistas e a coordenação do curso, sendo eles o e-mail e uma rede social (Whats $A p p)$.

Após cadastramento dos inscritos na plataforma e início virtual do curso, foi realizado o primeiro encontro presencial, que ocorreu na primeira semana do curso. Nele, foram explicados os objetivos do curso e da pesquisa, sendo solicitado, para os que concordassem em participar, que preenchessem o TCLE e o questionário ACAS para levantamento de concepções acerca das AH/SD.

Inicialmente, todos preencheram os documentos solicitados e, ao final de cada disciplina, os cursistas realizavam uma tarefa para que fossem verificadas eventuais dúvidas sobre os conteúdos e que poderiam ser retomadas no encontro presencial. Essas atividades também serviram como medida de avaliação do desempenho da turma ao longo do curso.

Além dos materiais de estudo obrigatório, foram disponibilizadas como leituras complementares a Resolução CNE/CEB 4 (BRASIL, 2009), a Resolução SE 81 (SÃO PAULO, 2012) e a leitura das páginas 57 a 62 do livro Encorajando Potenciais (VIRGOLIM, 2007).

Nos encontros presenciais, foram abordados os mesmos temas apresentados nas disciplinas online, de modo a dirimir dúvidas e aprofundar o assunto abordado, além de trazer experiências práticas, como o depoimento de um superdotado adulto e o manuseio de instrumentos de identificação e de elaboração de propostas de enriquecimento curricular.

Como os encontros presenciais foram voltados para a prática, os cursistas tiveram que realizar duas tarefas. A primeira foi mapear sua turma e a segunda elaborar uma proposta de enriquecimento curricular. Para realização dessas práticas foram utilizados instrumentos de triagem, modelos de elaboração de portfólio e de parecer pedagógico elaborados por Pérez e Freitas (2016) e a ficha "O que eu quero saber" publicada no livro "A construção de práticas educacionais para estudantes com altas habilidades/superdotação" (FLEITH, 2007, p. 97).

As atividades proporcionaram o levantamento inicial de 17 estudantes com indicadores de $\mathrm{AH} / \mathrm{SD}$, sendo que oito deles eram meninas. Houve orientação aos professores para que encaminhassem os estudantes à Clínica de Psicologia Aplicada, com a finalidade de serem avaliados pelo Projeto de Extensão "Identificação de estudantes com habilidades superiores e aconselhamento de pais e equipe escolar". O projeto objetiva avaliar estudantes com indicadores de AH/SD de maneira multimodal, com vistas ao encaminhamento para serviços especializados (ARANTES-BRERO, OLIVEIRA; CAPELLINI, 2018).

\footnotetext{
${ }^{1}$ As tutoras foram uma mestranda e uma doutoranda do Programa de Psicologia do Desenvolvimento e Aprendizagem, que fazem pesquisas na área das altas habilidades/superdotação.
} 
No último encontro presencial, os professores responderam novamente o ACAS para verificar se houve alguma mudança de concepção e realizaram o preenchimento do formulário de avaliação do curso para verificar se as expectativas e os objetivos propostos haviam sido alcançados.

Os dados coletados foram tabulados e analisados de modo descritivo e comparativo, considerando a intervenção. A estatística descritiva para os dados quantitativos foi realizada com o software Statistical Package for the Social Sciences (SPSS) v. 25, com análise por meio do teste não paramétrico de Wilcoxon e, para verificar a normalidade da distribuição da amostra, foi utilizado o teste Shapiro-Wilk, ambos com nível de significância de 0,05.

Para a questão descritiva do ACAS (O que é superdotação? Quais características de pessoas superdotadas?), procedeu-se à análise textual dos dados qualitativos com uso do software Iramuteq, sendo produzidas nuvens de palavras.

\section{Resultados}

Compuseram a amostra por conveniência 30 cursistas concluintes do curso. Destes, 29 (97\%) eram do sexo feminino, com média de idade de 39 anos $(\mathrm{W}=0,970 \mathrm{p}=0,526)$ e média de atuação no magistério de 14 anos $(\mathrm{W}=0,967 \mathrm{p}=0,469)$, sendo que $11(27,5 \%)$ possuíam especialização e um $(2,5 \%)$ mestrado. Dos que declararam ter especialização, sete (17,5\%) possuem formação na área da Educação Especial ou Inclusiva. Além disso, sete professores cursaram mais de uma graduação, 24 (60\%) possuem graduação em Pedagogia, seis (15\%) Licenciatura em Letras e três (7,5\%) Licenciatura em Matemática.

Ao todo, foram recebidas 24 avaliações do curso e $100 \%$ dos cursistas avaliaram que os objetivos foram cumpridos e suas expectativas atendidas. Do total de cursistas, 21 avaliaram como ótima a metodologia empregada nos encontros presenciais e 22 avaliaram como ótimo os professores responsáveis pelos encontros presenciais. Com relação à qualidade do curso online, 14 avaliaram como ótimo, oito como bom, um como ruim e um não respondeu.

Em relação à organização do curso, 18 consideraram ótimo, 5 bom e 1 não respondeu. Quanto à avaliação geral do curso, 22 consideraram ótimo, 1 bom e 1 não respondeu e 100\% deles afirmaram que recomendariam o curso para outras pessoas.

O questionário ACAS foi preenchido pelos participantes no início para verificar as concepções que eles tinham sobre as $\mathrm{AH} / \mathrm{SD}$, e ao final para medir o aproveitamento do curso de extensão. Os resultados seguem apresentados na Tabela 1. É importante mencionar que os participantes deveriam discordar da maioria das afirmativas, tendo em vista que elas eram falsas e baseadas em mitos acerca do tema. Vale ressaltar que a única afirmativa cuja resposta correta é "concordo" era a cinco. Nas demais questões, a resposta correta é "discordo" (WINNER, 1998). 
Tabela 1 - Frequência absoluta e relativa da distribuição das respostas pré e pós teste da ACAS

Questão

\begin{tabular}{|c|c|c|c|c|c|c|c|c|c|c|}
\hline \multicolumn{6}{|c|}{ Pré-intervenção } & \multicolumn{5}{|c|}{ Pós-intervenção } \\
\hline & & & & & & & C & & & NSR \\
\hline $\mathbf{F a}$ & $\begin{array}{c}\mathrm{Fr} \\
(\%)\end{array}$ & $\mathbf{F a}$ & $\begin{array}{c}\mathrm{Fr} \\
(\%)\end{array}$ & $\mathbf{F a}$ & $\begin{array}{c}\mathrm{Fr} \\
(\%)\end{array}$ & $\begin{array}{l}\text { F } \\
\text { a }\end{array}$ & $\begin{array}{c}\mathrm{Fr} \\
(\%)\end{array}$ & $\mathbf{F a}$ & $\begin{array}{c}\mathrm{Fr} \\
(\%)\end{array}$ & \\
\hline
\end{tabular}

1. Crianças academicamente superdotadas

\begin{tabular}{llllllllllll}
\hline & 20 & 23 & 77 & 1 & 3 & 2 & 7 & 28 & 93 & 0 & 0
\end{tabular}

possuem um poder intelectual geral que as

torna superdotadas em todas as disciplinas

escolares.

2. O QI acima da média é o que identifica

a pessoa com superdotação.

3. Os superdotados são as crianças com

alta habilidade em áreas acadêmicas.

4. A criança talentosa não é sinônimo de criança com superdotação.

5. As crianças com alta habilidade em

música e artes são talentosas.

6. Aluno com superdotação não é aluno

da Educação Especial.

7. Todo aluno com superdotação pode ser considerado um gênio.

8. A superdotação é inteiramente uma questão de trabalho duro.

9. Aluno com altas habilidades não é o mesmo que aluno com superdotação.

10. Aceleração do ensino para aluno com altas habilidades ou superdotação é a possibilidade de o aluno não cursar o ensino fundamental e ser matriculado automaticamente no ensino médio.

11. A superdotação em qualquer domínio depende de um QI alto

12. As crianças superdotadas são criadas por pais exigentes que levam os filhos a superdesempenhar-se.

13. Capacidades naturais são inatas e, por isso, fixas. Como qualquer predisposição genética, não têm necessidade de ensino ou aprendizagem estruturada.

$\begin{array}{llllllllllll}13 & 43 & 10 & 33 & 7 & 24 & 7 & 23 & 23 & 77 & 0 & 0 \\ 17 & 57 & 12 & 40 & 1 & 3 & 9 & 30 & 20 & 67 & 1 & 3 \\ 17 & 57 & 10 & 33 & 3 & 10 & 19 & 63 & 11 & 37 & 0 & 0 \\ 20 & 66 & 7 & 23 & 3 & 10 & 22 & 73 & 7 & 23 & 1 & 4 \\ 2 & 7 & 24 & 80 & 4 & 13 & 0 & 0 & 30 & 100 & 0 & 0 \\ 2 & 7 & 25 & 83 & 3 & 10 & 3 & 10 & 27 & 90 & 0 & 0 \\ 5 & 17 & 24 & 80 & 1 & 3 & 9 & 30 & 21 & 70 & 0 & 0 \\ 12 & 40 & 10 & 33 & 8 & 27 & 9 & 30 & 20 & 67 & 1 & 3 \\ 4 & 13 & 24 & 80 & 2 & 7 & 2 & 7 & 27 & 90 & 1 & 33\end{array}$

$\begin{array}{llllllllllll}9 & 30 & 11 & 37 & 10 & 33 & 5 & 17 & 25 & 83 & 0 & 0 \\ 0 & 0 & 30 & 100 & 0 & 0 & 0 & 0 & 30 & 100 & 0 & 0 \\ 1 & 3 & 25 & 84 & 4 & 13 & 5 & 17 & 24 & 80 & 1 & 3\end{array}$

\begin{tabular}{|c|c|c|c|c|c|c|c|c|c|c|c|c|}
\hline \multirow{4}{*}{ Questão } & \multicolumn{6}{|c|}{ Pré-intervenção } & \multicolumn{6}{|c|}{ Pós-intervenção } \\
\hline & & & & & & & & & & & & \\
\hline & \multicolumn{2}{|c|}{$\mathbf{C}$} & \multicolumn{2}{|c|}{ D } & \multicolumn{2}{|c|}{ NSR } & \multicolumn{2}{|c|}{$\mathrm{C}$} & \multicolumn{2}{|c|}{ D } & \multicolumn{2}{|c|}{ NSR } \\
\hline & $\mathbf{F a}$ & $\begin{array}{c}\text { Fr } \\
(\%)\end{array}$ & $\mathbf{F a}$ & $\begin{array}{c}\text { Fr } \\
(\%)\end{array}$ & $\mathbf{F a}$ & $\begin{array}{c}\text { Fr } \\
(\%)\end{array}$ & $\mathbf{F a}$ & $\begin{array}{c}\mathrm{Fr} \\
(\%)\end{array}$ & $\mathbf{F a}$ & $\begin{array}{c}\text { Fr } \\
(\%)\end{array}$ & & $\begin{array}{c}\text { Fr } \\
(\end{array}$ \\
\hline $\begin{array}{l}\text { 14.As crianças superdotadas, quando são } \\
\text { exigidas demais por seus pais, têm a } \\
\text { possibilidade de sucesso aumentada. }\end{array}$ & 7 & 23 & 20 & 67 & 3 & 10 & 9 & 30 & 19 & 63 & 2 & 7 \\
\hline $\begin{array}{l}\text { 15. As crianças superdotadas são melhor } \\
\text { ajustadas, mais populares e mais felizes do } \\
\text { que as crianças médias. }\end{array}$ & 2 & 7 & 27 & 90 & 1 & 3 & 0 & 0 & 30 & 100 & 0 & 0 \\
\hline $\begin{array}{l}\text { 16. Todas as crianças são superdotadas; } \\
\text { não há, portanto, nenhum tipo especial de } \\
\text { crianças que precise de educação } \\
\text { enriquecida ou acelerada nas nossas } \\
\text { escolas. }\end{array}$ & 0 & 0 & 29 & 97 & 1 & 3 & 0 & 0 & 30 & 100 & 0 & 0 \\
\hline
\end{tabular}




\begin{tabular}{|c|c|c|c|c|c|c|c|c|c|c|c|c|}
\hline $\begin{array}{l}\text { 17. As crianças superdotadas, } \\
\text { especialmente os prodígios, seguem } \\
\text { adiante para tornar-se adultos criativos e } \\
\text { eminentes. }\end{array}$ & 6 & 20 & 19 & 63 & 5 & 17 & 10 & 30 & 20 & 70 & 0 & 0 \\
\hline $\begin{array}{l}\text { 18. A superdotação é um fenômeno } \\
\text { extremamente raro, que dependente das } \\
\text { condições ambientais em que a pessoa } \\
\text { vive. }\end{array}$ & 1 & 3 & 27 & 90 & 2 & 7 & 0 & 0 & 29 & 96 & 1 & 3 \\
\hline $\begin{array}{l}\text { 19. Alunos superdotados destacam-se em } \\
\text { todas as áreas. }\end{array}$ & 0 & 0 & 26 & 87 & 4 & 13 & 0 & 0 & 30 & 100 & 0 & 0 \\
\hline $\begin{array}{l}\text { 20. Pessoas com superdotação são } \\
\text { autossuficientes e, por apresentarem uma } \\
\text { capacidade diferenciada, são capazes de } \\
\text { desenvolver suas habilidades por si sós, } \\
\text { não necessitando serviços diferenciados. }\end{array}$ & 2 & 7 & 26 & 86 & 2 & 7 & 29 & 97 & 1 & 3 & 0 & 0 \\
\hline $\begin{array}{l}\text { 21. Pessoas superdotadas provêm de } \\
\text { ambientes socialmente bem favorecidos. }\end{array}$ & 1 & 3 & 29 & 97 & 0 & 0 & 0 & 0 & 30 & 100 & 0 & 0 \\
\hline
\end{tabular}

Legenda: C - Concordo D - Discordo NSR - Não sei responder Fa-Frequência Absoluta Fr - Frequência Relativa

Fonte: Elaborada pelos autores (2021).

Os resultados demonstraram aumento no percentual de acertos em 15 questões $(1,2,3,4,6,7$, 9, 10, 11, 15, 16, 17, 18, 19 e 21), sendo que destas, 3 tiveram diferenças significativas (3, 17 e 19). Houve ainda, diminuição do número de acertos em quatro questões $(8,13,14$ e 20), com significância estatística nas questões 8 e 13.

A análise da pergunta aberta do questionário "O que é Superdotação? Quais características de pessoas superdotadas?" foi realizada com software estatístico Iramuteq, sendo analisada a nuvem de palavras, que permite o agrupamento e organização gráfica de palavras de acordo com sua frequência, possibilitando a visualização rápida das mais citadas no corpus textual analisado.

Figura 1 - Nuvem de palavras pré-teste

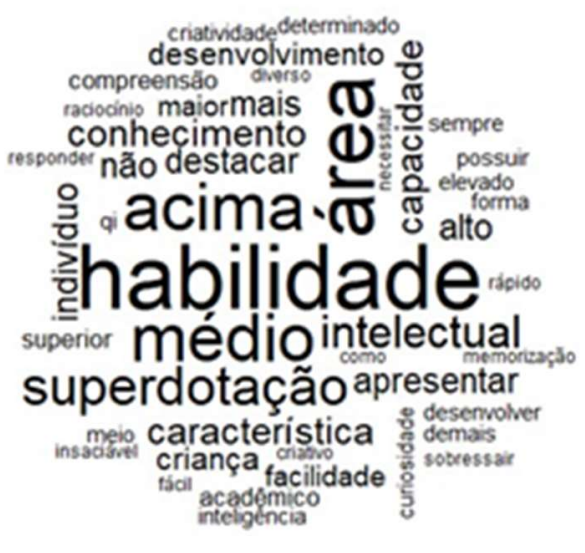

Fonte: Elaborada pelos autores (2021).

Ao observar-se a nuvem de palavras contida na Figura 1, é possível notar que as mais citadas pelos professores para descrever os estudantes superdotados são: habilidade (25 ocorrências), área (22), médio e acima (18 ocorrências cada), superdotação (14 citações), intelectual (11 ocorrências), seguidas de 
conhecimento, característica e capacidade ( 9 ocorrências cada). A Figura 2 demonstra o resultado da nuvem de palavras pós-teste.

Figura 2 - Nuvem de palavras pós-teste

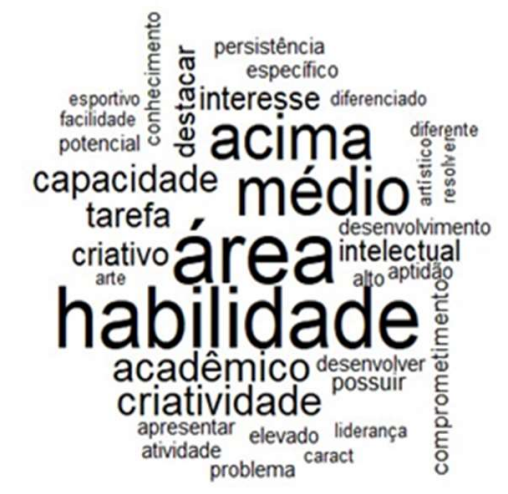

Fonte: Elaborada pelos autores (2021).

A nuvem de palavras resultante do preenchimento do ACAS pós-intervenção traz as mesmas palavras do pré-teste, com incidências parecidas, sendo elas: área (24 ocorrências), habilidade (23), médio (18 citações), acima (17) e capacidade ( 9 ocorrências), acrescida das novas palavras acadêmico (10 ocorrências), criatividade (10), tarefa (8 ocorrências), criativo e interesse (7 citações cada).

Outro achado pertinente refere-se à baixa procura dos professores para a realização do curso, tendo em vista que foram ofertadas 60 vagas e recebidas apenas 48 inscrições. Importante mencionar que as inscrições ocorreram a partir de livre demanda dos professores.

Segundo os próprios cursistas, o curso foi de grande importância para ampliar o olhar em relação ao estudante com $\mathrm{AH} / \mathrm{SD}$, que muitas vezes permanece invisível na escola. Dessa forma, os professores relataram que se sentem mais capazes de reconhecer e oferecer estratégias pedagógicas que atendam às necessidades dos estudantes. Além disso, todos apontaram que o conteúdo abordado é exequível em sala de aula podendo beneficiar a todos os alunos. As atividades práticas desenvolvidas buscaram ensinar procedimentos para a identificação e a construção de propostas de enriquecimento curricular para estes estudantes com o uso de instrumentos disponíveis na literatura. Deste modo, foi possível rastrear 17 estudantes com indicadores de AH/SD para posterior avaliação e confirmação diagnóstica.

\section{Discussão}

Os dados provenientes das questões fechadas do ACAS apontam melhora no desempenho da turma após a intervenção, corroborando o estudo de Lopes (2015). Um fato a ser mencionado refere-se à compreensão dos professores, sinalizada no pós-teste: os superdotados fazem parte do público-alvo da educação especial, conforme legislação vigente (BRASIL, 2008; SABBAG; ARANTES-BRERO, 2017), 
pois $100 \%$ discordaram da afirmação contida na questão 6 (Aluno com superdotação não é aluno da Educação Especial).

No que concerne às questões que obtiveram aumento no número de acertos com significância estatística, nota-se a quebra de 3 mitos (superdotados são as crianças com alta habilidade em áreas acadêmicas, superdotação é um fenômeno extremamente raro e pessoas superdotadas são autossuficientes) apontados pela literatura (WINNER, 1998).

Em relação ao mito de que superdotados são crianças com alta habilidade em áreas acadêmicas, a própria legislação brasileira refere a existência de habilidades acima da média em áreas isoladas ou combinadas (intelectual, acadêmica, liderança, psicomotricidade e artes), além de apresentarem elevada criatividade e envolvimento em área de seu interesse (BRASIL, 2008). Renzulli (2018) afirma a existência de dois tipos de superdotação, a escolar e a criativo-produtiva. É incorreto afirmar, portanto, que as $\mathrm{AH} / \mathrm{SD}$ estejam associadas apenas às questões acadêmicas, pois essa premissa desconsideraria os diversos perfis de superdotação existentes.

No que concerne ao mito de que a superdotação é um fenômeno extremamente raro, que depende das condições ambientais em que a pessoa vive, Antipoff e Campos (2010) alertam para a ideia equivocada de que só existem pessoas com $\mathrm{AH} / \mathrm{SD}$ nas camadas mais privilegiadas, pois, em tese, elas possuem maior acesso a situações estimulantes. Os autores salientam que essas pessoas podem estar presentes nas camadas socioeconomicamente desprivilegiadas, sendo importante que seu reconhecimento se dê de modo precoce. Assim, poderão ser oferecidas condições de desenvolvimento que levem ao direcionamento desses talentos para a produção de soluções que impactem positivamente seu entorno. Ainda sobre este mito, vale destacar que o Relatório de Marland (1972) aponta a existência de, pelo menos, $3 \%$ a 5\% de pessoas superdotadas na população geral, não sendo tão rara, como aponta Silva-Schröeder (2020).

O mito de que as pessoas superdotadas são autossuficientes também pode ser quebrado com base na legislação brasileira, tendo em vista que, por fazerem parte da educação especial, esses estudantes devem receber suporte às suas demandas específicas (BRASIL, 2008). Ideal, então, que o professor saiba identificar essa população, para oferecer o enriquecimento ou aprofundamento do currículo por meio do Atendimento Educacional Especializado (SABBAG; ARANTES-BRERO, 2017).

Por outro lado, é preciso discutir a diminuição do número de acertos com significância estatística nas questões 8 e 13. O mito de que altas habilidades não é o mesmo que superdotação acaba sendo muito reforçado pelas discussões em relação à terminologia, existentes entre diversos pesquisadores brasileiros. De acordo com Pérez (2003), a falta de universalização do conceito acarreta vários equívocos sobre o fenômeno. A multiplicidade de termos existentes dá a noção exata de como é complexo lidar com a subjetividade humana e encontrar padronizações que contemplem a multiplicidade de possibilidades existentes (ARANTES-BRERO, 2016; 2020). 
O mito apresentado na questão 13 (As crianças superdotadas, quando são exigidas demais por seus pais, têm a possibilidade de sucesso aumentada) fundamenta-se na ideia errônea de que os pais podem organizar a vida de seus filhos, levando-os a um desempenho excepcional. Não são os pais, no entanto, que criam superdotados, mas sim são as crianças que exigem um ambiente enriquecedor que supra seus interesses e curiosidades. A supervalorização da família sobre desempenho pode levar a desajustes emocionais na criança (PÉREZ, 2003; SILVA-SCHRÖEDER, 2020; WINNER, 1998).

Em relação à nuvem de palavras gerada a partir dos dados qualitativos do ACAS, os resultados indicam melhor compreensão dos cursistas em relação ao conceito de AH/SD baseado no modelo dos três anéis proposto por Renzulli $(2014$, 2018), que requer a combinação de habilidade acima da média, criatividade e envolvimento com a tarefa, por meio da utilização de palavras como criatividade, criativo, habilidade, acima e tarefa. Estes dados corroboram os achados da literatura que indicam a necessidade de oportunizar, por meio da formação continuada, condições para que o professor perceba indicadores de $\mathrm{AH} / \mathrm{SD}$ a partir da oferta de conceitos teóricos e práticos, bem como o conhecimento dos instrumentos disponíveis para as escolas (BERGAMIN, 2018; SOARES; CHACON, 2016), tais como os propostos pelo modelo de enriquecimento escolar delineado por Renzulli (2018).

De acordo com Manso (2012), muitas ideias errôneas já foram superadas, mas alguns mitos ainda persistem e interferem na identificação e atendimento desses estudantes. Assim, é preciso aprofundar os estudos na área, com pesquisas que indiquem novos apontamentos e instrumentos para a identificação desse alunado (MARTINS; PEDRO; ODEGA, 2016).

\section{Conclusão}

O curso foi desenvolvido dentro do esperado, sendo importante ressaltar a baixa procura por inscrições tendo em vista que foram ofertadas 60 vagas e recebidas apenas 48 inscrições. Um aspecto positivo refere-se ao interesse dos professores que se inscreveram e mantiveram-se motivados e participativos ao longo do processo, realizando atividades interessantes e completas. Esse bom desempenho pode ter relação com o fato de terem escolhido fazer o curso, não sendo designados para tal por instâncias superiores. Além disso, a atuação constante das tutoras e a facilidade dos cursistas em tirarem suas dúvidas com a coordenação, por meio dos canais disponibilizados, facilitou o andamento do curso.

Vale destacar, como um dos pontos fortes do curso, o fato de ele ser muito voltado para a prática pedagógica, orientando o professor sobre como fazer. Todos, desse modo, tiveram a oportunidade de mapear uma turma e localizar estudantes com potencial e, em seguida, experienciaram a construção de uma proposta de enriquecimento curricular de modo a contemplar as necessidades do estudante previamente indicado. Outro aspecto positivo refere-se ao fato de o curso ter uma parte teórica no AVA, 
com tarefas semanais, que ajudaram no engajamento dos cursistas. Eles tinham, ainda, oportunidade de discutir dúvidas nos encontros presenciais, articulando teoria e prática.

O fato de os cursistas terem que cumprir uma porcentagem de presença e poderem evoluir na carreira com o certificado do curso também auxiliou no engajamento e participação.

Quanto aos aspectos dificultadores, destaca-se que 20 professores relataram alguma dificuldade em utilizar o AVA e dois deles mencionaram muita dificuldade. Isso denota que ainda precisa ser realizado investimento na formação dos professores para o uso das tecnologias digitais e de comunicação. Outra questão refere-se à dificuldade de alguns em cumprir as tarefas práticas nas suas escolas de origem, por encontrarem barreiras: dentre elas, o desinteresse de outros professores em realizar o mapeamento da turma, a falta de articulação entre sala de recursos e classe comum e a dificuldade em fazer contato com os pais para preenchimento dos questionários específicos.

De modo geral, foi possível observar um incremento na formação dos professores acerca do tema das $\mathrm{AH} / \mathrm{SD}$ por meio da melhora no desempenho pré e pós-intervenção, em termos de aumento no número de acertos das questões propostas pelo ACAS. No entanto, não se pode perder de vista que, apesar de uma melhora nos resultados, a análise estatística demonstrou pouca significância na maioria das questões, sendo que esta ocorreu em apenas cinco delas, incluindo duas em que houve decréscimo no número de acertos.

Esse dado reforça a importância de investir em formação de professores, a qual deve ser encarada como uma política pública que urge ser implementada, especialmente em relação ao tema abordado neste curso. Desse modo, pretende-se ampliar a identificação dos estudantes, para que possam ser desenhadas políticas em larga escala com encorajamento de potenciais. 


\section{REFERÊNCIAS}

ANTIPOFF, Cecília Andrade; CAMPOS, Regina Helena de Freitas. Superdotação e seus mitos. Psicol. Esc. Educ. (Impr.), Campinas, v. 14, n. 2, p. 301-309, dez. 2010. Disponível em:

https://www.scielo.br/j/pee/a/cFcPTS7QRGqk9mKZsW5tWVz/?format=pdf\&lang=pt. Acesso em: 13 set. 2021.

ARANTES-BRERO, Denise Rocha Belfort; OLIVEIRA, Ana Paula de; CAPELLINI, Vera Lúcia Messias Fialho. Identificação de estudantes com indicativos de altas habilidades/superdotação e aconselhamento para pais e equipe escolar. Anais do $1^{\circ}$ Congresso Brasileiro de Educação para Altas Habilidades/Superdotação: concepções, práticas e tecnologias. Londrina/PR: Colégio Mãe de Deus, 2018.

ARANTES-BRERO, Denise Rocha Belfort. Os talentos e a cultura: a trajetória de Anita Malfatti. Revista Educação Especial, Santa Maria, p. 399-412, ago. 2016. Disponível em: https://periodicos.ufsm.br/educacaoespecial/article/view/19169. Acesso em: 13 set. 2021.

ARANTES-BRERO, Denise Rocha Belfort. Altas Habilidades/Superdotação na vida adulta. 1 ed. Curitiba: Juruá, 2020. v. 1.95p.

BAHIENSE, Taisa Rodrigues Smarssaro; ROSSETTI, Claudia Broetto. Altas Habilidades/superdotação no Contexto escolar: percepções de professores e prática docente. Rev. Bras. Ed. Esp., Marília, v. 20, n. 2, p. 195-208, Abr.-Jun., 2014. Disponível em:

https://www.scielo.br/j/rbee/a/kTN4Ps4FsWX76L65ZYjVntg/abstract/?lang=pt. Acesso em: 13 set. 2021.

BERGAMIN, Aletéia Cristina. Enriquecimento curricular na classe comum a partir das necessidades de alunos com altas habilidades/superdotação. 2018. 125f. Dissertação (Mestrado Profissional) - UNESP, Faculdade de Ciências, Bauru, 2018. Disponível em: https://repositorio.unesp.br/handle/11449/153376. Acesso em: 13 set. 2021.

BORGES, Patrícia Bisso Paz. Formação continuada de professores: uma revisão de literatura em trabalhos publicados de 2005 a 2015. 2016. 36f. Trabalho de Conclusão de Curso (Licenciatura em Química) Universidade Federal do Pampa, Caçapava do Sul, 2016. Disponível em:

http://cursos.unipampa.edu.br/cursos/cienciasexatas/files/2014/06/TCC. Acesso em: 13 set. 2021.

BRASIL. Lei No 9.394, de 20 de dezembro de 1996. Disponível em: http://www.planalto.gov.br/ccivil 03/leis/19394.htm. Acesso em: 25 jul. 2019.

BRASIL. Política Nacional de Educação Especial na Perspectiva da Educação Inclusiva. Brasília. Grupo de Trabalho da Política Nacional de Educação Especial, 2008. Disponível em: http://portal.mec.gov.br/arquivos/pdf/politicaeducespecial.pdf. Acesso em: 10 jul. 2019.

BRASIL. Resolução No 4, de 2 de outubro de 2009. Brasília-DF: Ministério da Educação. Conselho Nacional de Educação. Câmara de Educação Básica. Disponível em:

http://portal.mec.gov.br/dmdocuments/rceb004 09.pdf. Acesso em: 25 jul. 2019.

BRASIL. Decreto $N^{0} 7.611$, de 17 de novembro de 2011. Disponível em: http://www.planalto.gov.br/ccivil 03/ Ato2011-2014/2011/Decreto/D7611.htm. Acesso em: 25 jul. 2019.

BRASIL. Lei No 13.234, de 29 de dezembro de 2015. Disponível em: https://www2.camara.leg.br/legin/fed/lei/2015/lei-13234-29-dezembro-2015-782192-norma-pl.html. Acesso em: 25 jul. 2019. 
CAPELLINI, Vera Lúcia Messias Fialho. Adaptações curriculares na inclusão escolar. contrastes e semelhanças entre dois países. 1 ed. Curitiba/PR: Appris, 2018. v. 1. 273p.

COZBY, Paul. Métodos de pesquisa em ciências do comportamento. São Paulo: Atlas, 2003.

FLEITH, Denise de Souza. A construção de práticas educacionais para alunos com altas habilidades/superdotação, v. 2. Brasília, DF: MEC, 2007. Disponível em: http://portal.mec.gov.br/seesp/arquivos/pdf/altashab3.pdf. Acesso em: 13 set. 2021.

INSTITUTO NACIONAL DE ESTUDOS E PESQUISAS EDUCACIONAIS ANÍSIO TEIXEIRA (INEP). Diretoria de Estatísticas Educacionais. Resultados do Censo de Educaşão Básica, 2019. Disponível em: https://inepdata.inep.gov.br/analytics/saw.dll?Dashboard. Acesso em: 13 set. 2021.

LÔBO, Tânia Naves Nogueira. Perfil do aluno superdotado: análise de dossiês de alunos participantes de uma sala de recursos no período de 1999 a 2013. Dissertação (Mestrado em Processos de Desenvolvimento Humano e Saúde). Universidade de Brasília, Instituto de Psicologia, Brasília- DF, 2016, 86p. Disponível em: https://repositorio.unb.br/handle/10482/20109. Acesso em: 13 set. 2021.

LOPES, Jéssica Fernanda; LENHARO, Naira Ruiz; CAPELLINI, Vera Lúcia Messias Fialho. Formação docente sobre altas habilidades / superdotação e a construção da escola inclusiva. Interciência \& sociedade, v. 3, n. 2, 2014. Disponível em: https://repositorio.unesp.br/handle/11449/135422. Acesso em: 13 set. 2021.

LOPES, Jessica Fernanda. Dotação e talento: comparação das modalidades presencial e a distância de um programa de formação continuada para professores. 2015. 136 f. Dissertação (mestrado) - Universidade Estadual Paulista Júlio de Mesquita Filho, Faculdade de Ciências, 2015. Disponível em: https://repositorio.unesp.br/handle/11449/123729. Acesso em: 13 set. 2021.

MANSO, Renata Sayão Araujo. Concep̧cões e mitos sobre superdotação: o que pensam professores de crianças pequenas? (Dissertação Mestrado em Educação) Universidade Católica de Brasília, Brasília, DF, Brasil, 2012. Disponível em:

https://bdtd.ucb.br:8443/jspui/bitstream/123456789/705/1/Renata\%20Sayao\%20Araujo\%20Manso. pdf. Acesso em: 13 set. 2021.

MARLAND. Education of the gifted and talented. Report to Congress. Washington, DC: Documento oficial, 1972. Disponível em: https://www.valdosta.edu/colleges/education/humanservices/document $\% 20 /$ marland-report.pdf. Acesso em: 13 set. 2021.

MARTINS, Alexandra da Costa Souza; ALENCAR, Eunice Soriano de. Características desejáveis em professores de alunos com altas habilidades/superdotação. Rev. Educ. Espec., Santa Maria, v. 24, n. 39, p. 31-46, jan./abr. 2011. Disponível em: https://periodicos.ufsm.br/educacaoespecial/article/view/1881. Acesso em: 13 set. 2021.

MARTINS, Bárbara Amaral; CHACON, Miguel. Identificação de características de altas habilidades/superdotação apresentadas por alunos matriculados em escolas de ensino regular. Trabalho apresentado no IX ANPED Sul. Caxias do Sul, UCS, 2012. Disponível em:

https://periodicos.ufsm.br/educacaoespecial/article/view/1881. Acesso em: 13 set. 2021.

MARTINS, Bárbara Amaral, PEDRO, Ketilin Mayra; OGEDA, Clarissa Marques Maria. Altas habilidades/superdotação: o que dizem as pesquisas sobre estas crianças invisíveis?. Psicologia Escolar e Educacional, v. 20, n. 3, p. 561-568, 2016. Disponível em: https://www.marilia.unesp.br/Home/Extensao/papah/identificacao ah-sd.pdf. Acesso em: 13 set. 2021. 
MARTINS, Bárbara Amaral; CHACON, Miguel; ALMEIDA, Leandro. Estudo comparativo lusobrasileiro sobre a formação inicial de professores em altas habilidades/superdotação com enfoque nos conteúdos curriculares. Rev. Bras. Ed. Esp., Marília, v. 24, n. 3, p. 309-326, jul./set., 2018. Disponível em: https://www.scielo.br/j/rbee/a/BjsNxNZfz4yBkQMsWkT9GSB/abstract/?lang=pt. Acesso em: 13 set. 2021.

MATOS, Nathalia Cristina; SOUZA, Edison Roberto de; NASCIMENTO, Juarez Vieira do; PINTO, Marilia Garcia; SOUZA, Alba Regina Battisti de. A formação continuada de professores da educação básica uma revisão sistemática. Cadernos de Pesquisa: Pensamento educacional, Curitiba, v. 11, n. 28, p. 45-64, mai./ago. 2016. Disponível em: https://seer.utp.br/index.php/a/article/view/311. Acesso em: 13 set. 2021.

MORI, Nerli Nonato Ribeiro; BRANDÃO, Silvia Helena Altoé. O atendimento em salas de recursos para alunos com altas habilidades/superdotação: o caso do Paraná. Rev. Bras. Ed. Esp., Marília, v. 15, n. 3, p. 485-498, set./dez., 2009. Disponível em:

https://www.scielo.br/j/rbee/a/753gd8JP3Qkvwg4K7YQk9xj/?lang=pt\&format=pdf. Acesso em: 13 set. 2021.

PÉREZ, Suzana Graciela Pérez Barrera. Mitos e crenças sobre as pessoas com altas habilidades: alguns aspectos que dificultam o seu atendimento. Cadernos de Educaşão Especial, Santa Maria, v. 2, n. 22, p. 4559, 2003. Disponível em: https://periodicos.ufsm.br/educacaoespecial/article/view/5004/3033. Acesso em: 13 set. 2021.

PÉREZ, Suzana Graciela Pérez Barrera; FREITAS, Soraia Napoleão. Encaminhamentos pedagógicos com alunos com Altas Habilidades/Superdotação na Educação Básica: o cenário Brasileiro. Educar em Revista, n. 41, p.109-124, 01 set., 2011. Disponível em:

https://www.scielo.br/j/er/a/hv87YLFWx6BGY7C8JCNqWiP/?lang=pt. Acesso em: 13 set. 2021.

PÉREZ, Suzana Graciela Pérez Barrera; FREITAS, Soraia Napoleão. Manual de identificação de altas habilidades/superdotação. Guarapuava: Apprehendere, 2016.

RAMALHO, Jairo et al.. A carência de formação sobre a superdotação nas licenciaturas da UFPE 1: Um estudo de caso. Revista Brasileira de Educação Especial, v. 20, n. 2, p.235-248, abr./jun. 2014. Disponível em: https://www.scielo.br/j/rbee/a/9YQRsxYyBygyH9XK5kfHwFw/?lang=pt. Acesso em: 13 set. 2021.

RENZULLI, Joseph. Salvatore. Concepção de superdotação no modelo dos três anéis: um modelo de desenvolvimento para a promoção da produtividade criativa. In: VIRGOLIM, Angela Mágda; KONKIEWITZ, Elisabete Castelon (Orgs.). Altas habilidades/superdotação, inteligência e criatividade. Campinas, SP: Papirus Editora, 2014, p. 219-264.

RENZULLI, Joseph. Salvatore. Reexaminando o papel da educação para superdotados e o desenvolvimento de talentos para o século XXI: uma abordagem teórica em quatro partes. In: VIRGOLIM, Angela Magda Rodrigues (Org.). Altas habilidades/superdotação: processos criativos, afetivos e desenvolvimento de potenciais. Curitiba, PR: Juruá Editorial, 2018, p. 19-42.

RODRIGUES, L. M. Altas Habilidades/Superdotação: levantamento de crianças com esses indicadores e concepção de professores sobre o tema. (Monografia). Curso de Pedagogia. Universidade Estadual Paulista "Júlio de Mesquita Filho” (UNESP), Bauru, 2012. Não publicado.

SABBAG, Gregório Paoli C., ARANTES-BRERO, Denise Rocha Belfort. Mitos e crenças sobre altas habilidades ou superdotação entre professores de uma escola da DRE Pirituba/ Jaraguá. InFor, Inov. Form., Rev. NEaD-Unesp, São Paulo, v. 3, n. 2, p. 168-200, 2017. Disponível em: https://ojs.ead.unesp.br/index.php/nead/article/view/442. Acesso em: 13 set. 2021. 
SÃO PAULO. Resolução SE 81 de 7 de agosto de 2012. Dispõe sobre o processo de aceleração de estudos para alunos com altas habilidades/superdotação na rede estadual de ensino e dá providências correlatas. Disponível em:

http://www.educacao.sp.gov.br/lise/sislegis/detresol.asp?strAto=201208070081. Acesso em: 13 set. 2021.

SILVA-SHRÖEDER, Christine da. $A$ diversidade invisivel: as pessoas com AH/SD e a vida profissional. Livro 1: primeiros olhares. Brasil: Amazon Publishing, 2020.

SOARES, Andréia Alves da Silva; CHACON, Miguel Cláudio Moriel. Identificação escolar de estudantes precoces com comportamento de superdotação no sistema regular de ensino: um desafio para a formação continuada de professores. Trabalho apresentado no I Congresso Internacional de Educação Especial e Inclusiva. 13ª Jornada de Educaşão Especial, Marília, 2016.

VIRGOLIM, Ângela Magda Rodrigues. Altas habilidades/superdotacão: encorajando potenciais. Brasília: Ministério da Educação, Secretaria de Educação Especial, 2007.

WECHSLER, Solange Muglia; SUAREZ, Janete Tonete. Percepção de professores em cursos de formação sobre talentos/superdotação. Psicologia, v. 34, n. 1, p. 39-60, 2016. Disponível em: http://pepsic.bvsalud.org/scielo.php? script $=$ sci abstract\&pid $=$ S025492472016000100003\&lng=pt\&nrm=iso. Acesso em: 13 set. 2021.

WINNER, Ellen. Crianças superdotadas: mitos e realidades. Porto Alegre: Artes Médicas, 1998.

Recebido em: 05 de abril de 2021. Aprovado em: 13 de setembro de 2021. 